Keywords: advanced ovarian cancer; chemotherapy treatments; supportive care; patients' views; oncologists' views; maintenance therapy

\title{
Patients' and oncologists' views on the treatment and care of advanced ovarian cancer in the UK: results from the ADVOCATE study
}

\author{
V Jenkins ${ }^{*}{ }^{1}$, S Catt ${ }^{1}$, S Banerjee ${ }^{2}$, C Gourley ${ }^{3}$, A Montes ${ }^{4}$, I Solis-Trapala ${ }^{1}$, K Monson ${ }^{1}$ and L Fallowfield ${ }^{1}$ \\ ${ }^{1}$ Sussex Health Outcomes Research and Education in Cancer (SHORE-C), Brighton and Sussex Medical School, University of \\ Sussex, Falmer, Brighton BN1 9QG, UK; ${ }^{2}$ The Royal Marsden NHS Foundation Trust Chelsea and SuttonDowns RdSM2 5PT, \\ Fulham Road, London SW3 6JJ, UK; ${ }^{3}$ Edinburgh Cancer Research Centre, MRC IGMM, Western General Hospital, University of \\ Edinburgh, Crewe Road South, Edinburgh EH4 2XR, UK and ${ }^{4}$ Medical Oncology, Guy's Hospital, 4th Floor, Bermondsey Wing, St \\ Thomas' Street, London SE1 9RT, UK
}

Background: Most patients presenting with advanced ovarian cancer $(A O C)$ eventually relapse. Symptom palliation, maintenance of quality of life $(\mathrm{Q} O L)$ and prolongation of life are primary therapeutic goals.

Methods: Sixty-six UK oncologists completed an online survey about AOC management. Two hundred and two patients were interviewed about care, treatment experiences and expectations.

Results: Prior to diagnosis, 34\% (69 out of 202) of women had $\geqslant 3$ symptoms associated with AOC. Twenty-one per cent (43 out of 202) thought poor symptom recognition by general practitioners (GPs) delayed diagnosis. Amelioration of side effects experienced was variable, for example, only $54 \%$ (68 out of 127) distressed by alopecia had received sufficient information about it. Clinicians were asked 'What minimum gain in progression-free survival (PFS) would make you feel it worthwhile to offer maintenance therapy?'; $48 \%$ (24 out of 50) indicated 5-6 months, but 52\% (26 out of 50) believed patients would find PFS of 3-4 months acceptable. When patients were presented with hypothetical scenarios, $33 \%$ (52 out of 160) would require 1-2 months extra life, $6 \%$ (10 out of 160) 3-4 months, 31\% (49 out of 160) 5-6 months, and 31\% (49 out of 160) $\geqslant 7$ months. However, $86 \%$ (173 out of 202) would accept treatment that improved QoL without prolongation of life. When asked what was most important, $33 \%$ (67 out of 201) said QoL, 9\% (19 out of 201) length of life and 57\% (115 out of 201) said both were equally important.

Conclusion: Clinicians' and patients' experiences, expectations and priorities about OC management may differ.

Ovarian cancer (OC) is the fifth most common cancer in UK women, affecting $\sim 6500$ women a year (Cancer Research UK, 2012). It is primarily a disease of older, postmenopausal women, and diagnosis and specialist referral is often delayed due to the insidious/vague nature of the presenting symptoms. By the time most women are diagnosed they have advanced disease (Stages II-IV) and the outcomes of UK patients are still poorer than in comparable countries (Coleman et al, 2011). However, fiveyear survival has increased from 33\% to $44 \%$ since 2001 in the UK and deaths have fallen by a fifth (Cancer Research UK, 2012).

The National Institute for Health and Clinical Excellence (NICE) technology appraisal guidance No. 55 (NICE, 2003) recommends that paclitaxel in combination with a platinum-based compound or platinum-based therapy alone are offered as part of a

*Correspondence: Dr VA Jenkins; E-mail: val@sussex.ac.uk

Received 30 January 2013; revised 4 April 2013; accepted 17 April 2013; published online 7 May 2013

(c) 2013 Cancer Research UK. All rights reserved 0007-0920/13 
first-line treatment package that also includes maximal debulking surgery for patients with advanced disease. However, despite optimal primary therapy, recurrent disease is diagnosed in the majority of patients within 5 years (du Bois et al, 2009). The choice of subsequent therapy at the time of progression or at relapse is dependent on the platinum-free interval. Options for platinumsensitive patients ( $>6$ months since last therapy) include platinum combinations (with pegylated liposomal doxorubicin hydrochloride (PLDH), paclitaxel and gemcitabine). For patients with platinum-resistant disease ( $<6$ months since last therapy), options include PLDH, weekly paclitaxel, topotecan and etoposide.

Addition of other drugs, such as bevacizumab to chemotherapy regimens has until very recently been predominantly limited to clinical trial settings. In December 2011, the European Medicines Agency (EMA) approved bevacizumab for use in combination with carboplatin and paclitaxel chemotherapy, then continued as singleagent maintenance therapy for a total of 15 months as a front-line treatment for women with stage IIIB-IV OC. In England, the National Institute for Clinical Excellence (NICE) is not due to report on their evaluations of bevacizumab until the summer of 2013. Although clinical trials have shown 3-4-month improvement in progression-free survival (PFS) (Burger et al, 2011; Perren et al, 2011) and evidence of improvement in overall survival (OS) for poor-risk subgroups (Kristensen et al, 2011), the prolonged maintenance phase of bevacizumab therapy, typically 8-12 months, and its cost may still prove to be a barrier to its adoption within the NHS. With regards to the clinical management of OC, there are few published data on variations in practice across the UK. Maintaining quality of life (QoL) is the main goal for these patients, together with symptom control and, if possible, prolongation of life. Continued contact with specialist nurses during maintenance treatment may be of benefit, in terms of offering reassurance and timely and appropriate supportive care (Cox et al, 2006; Cox et al, 2008).

The influence of social support and clinical outcome has recently been recognised in women with ovarian cancer (Lutgendorf et al, 2012). A higher level of social attachment (i.e. the subjective experience of close emotional bonds) is associated with survival advantage, which has implications for support activities during adjuvant cancer care and beyond. Some centres now use patientreported outcome (PROs) measures to help clinicians systematically identify and address symptoms of concern to the patient, which together with more traditional clinical objective measures, may lead to better decision making and tailoring of treatment. For example, adjusting chemotherapy dosing according to patient-reported severity of symptoms (Basch and Abernethy, 2011). In addition, patients may have different expectations about treatments and place different values on outcomes from those of health-care professionals (Meropol et al, 2008). They may have preferences about different types of management plans available in terms of treatment and its mode of delivery. Furthermore, health-care professionals may rate their expectations of minimum gain in terms of OS and PFS differently to what they believe their patients would consider. The purpose of this study was to examine the experiences and preferences of women with advanced OC for their care and treatment, and consider these results in terms of oncologists' current practice within the UK.

\section{PATIENTS AND METHODS}

Clinician survey. All oncologists treating women with advanced OC in the UK were invited to complete an online survey between October and December 2011 about their current clinical practice and views on managing women with advanced OC. This was prior to the decision to accept bevacizumab for advanced OC onto the priority list of the Cancer Drugs Fund (CDF) in England (The CDF ends April 2013 and its future is uncertain).

To ensure that the invitation was comprehensively distributed, the gynaecological lead clinician for every cancer network in England, Wales, Scotland and Northern Ireland was contacted and asked to supply contact details for oncologists treating women with OC or to forward the invitation directly. Additionally, the British Gynaecological Cancer Society alerted its membership by email and provided a website link to the survey. The clinician survey comprised five sections: (1) demographics: plus perceptions of symptoms most troubling to women presenting with OC, (2) routine NHS care for non-clinical trial patients: first-, second-line and subsequent treatments, (3) maintenance therapy: including opinions about minimum gain required for PFS and OS, (4) clinical trial participation and (5) availability of supportive care within their cancer centre/hospital.

Patient interviews. Women with stage II-IV OC recently completed or currently receiving chemotherapy were eligible to participate in the ADVOCATE (Advanced Ovarian Cancer: Care and Treatment Experiences) study. Sixteen hospitals in England, Scotland and Wales provided access to patients. Ethical approval (ref: 11/LO/1527), sponsorship and all local NHS R\&D permission was obtained for each hospital.

Interview. Structured interviews were conducted by experienced researchers (SC, VJ and LJF), and lasted between 30-45 min. Areas covered were: demography, medical/treatment history, comorbidities and medication, symptoms prior to diagnosis that prompted medical help seeking, most 'bothersome' treatment side effects and care received to ameliorate them, other support and help provided, preferences for future treatment/care and patients' views on maintenance therapy using a hypothetical scenario.

Standardised questionnaires. The European Organisation for Research and Treatment in Cancer Quality Life Questionnaire (EORTC QLQC30) (Aaronson et al, 1993) plus an ovarian cancer module (OV28) (Greimel et al, 2003) were administered and the EORTC INFO25 (Arraras et al, 2010) to record information needs. These standardised measures require Likert-type responses: 'not at all'; 'a little'; 'quite a bit'; 'very much'. Ratings are obtained for individual items, for subscale scores and a global score. The OV28 generates six symptom scales: abdominal/GI, peripheral neuropathy, hormonal, body image, attitude to disease/treatment, chemotherapy side effects and two additional items (other items and sexuality). The INFO25 comprises four multi-item scales (information about disease, medical tests, treatment and other services) and eight single items.

Treatment records. With the patient's consent, the gynaecology teams provided a record of the treatments administered for each woman.

Procedures. Eligible patients were invited to consider the study by a member of the gynaecology team and given an information pack to read. The pack contained a letter of invitation, a patient information sheet, an expression of interest (EOI) form and a prepaid return envelope. Those interested contacted the researchers directly either by returning the EOI forms, by email or telephone. Interviews were either conducted face to face or by telephone, at a mutually convenient time. The QoL questionnaires were completed during the same week as the interview and returned by post. Written informed consent was obtained prior to all data collection.

\section{Statistical methods}

Clinician survey and patient interviews. Summary statistics were generated for the clinician and patient interview data including: counts, percentages and means. 
Quality of life data and preferences. The global scores on the EORTC QLQC30 and INFO25 questionnaires were analysed using linear regression models. We dichotomised responses to questions 18 and 19 of the OV28 'hormonal' scale so that 'quite a bit/very much' indicated meaningful symptoms whereas 'not at all/a little' indicated no meaningful symptoms. We then fitted a logistic regression model to the dichotomised responses. Similarly, we fitted a logistic regression model to the 'attitude' scale items. These analyses were adjusted for age group, on/off treatment, partner/no partner and education. Responses to 'Would you take a drug that improved QoL but did not prolong life? (yes/no?)' were analysed using logistic regression models. We analysed the responses to 'Which is most important to you? (QoL, length of life or both?)' using a multi-nominal logistic regression to model log-odds of preferring 'QoL' over 'both' and 'length of life' over 'both'. Responses to the question 'How many extra years of life would make chemotherapy worthwhile? ('1-2 months', '3-4 months', '5-6 months' and '7 or more months'?)', defined an ordinal variable that was analysed using ordinal logistic regressions to estimate the log-odds of a longer versus a shorter timespan selected. These analyses were adjusted for QoL and INFO25 global scores in addition to age group, on/off treatment, partner/no partner and education.

Likelihood ratio tests were used for model selection, goodness of fit was assessed and model diagnoses were carried out.

\section{RESULTS}

\section{Clinicians and patients}

Demography. There are no accurate records of how many UK oncologists treat women with OC. However, the cancer network gynaecology team leads believed the majority of treating oncologists were canvassed, and 66 out of $92(70 \%)$ of them responded. Table 1a shows the clinicians' characteristics.

Clinic staff at the 16 centres distributed a total of 435 information packs to eligible patients; 225 out of 435 (52\%) patients returned EOI forms and 202 out of 225 (90\%) were interviewed. Mean time since diagnosis for participants was 31.5 months (s.d. 37 months). At the time of interview, 58\% (117 out of 202) of women were receiving chemotherapy. Patients' characteristics including details of surgery are displayed in Table $1 \mathrm{~b}$.

Symptoms. Prior to diagnosis, 34\% (69 out of 202) of women had three or more symptoms that prompted a visit to their general practitioner (GP); $31 \%$ (63 out of 202) had two symptoms, $29 \%$ (59 out of 202) one symptom and 5\% (11 out of 202) were diagnosed incidentally. Primary symptoms were abdominal swelling (53\%; 108 out of 202), abdominal pain (38\%; 78 out of 202) and fatigue $(20 \% ; 41$ out of 202$)$, suggesting that advanced disease was already present (see Figure 1). Oncologists ranked abdominal pain/discomfort $(33 \% ; 22$ out of 66$)$, and abdominal swelling (36\%; 24 out of 66$)$ as the most troublesome for patients at the time of clinical presentation.

Patients made many comments about their experiences prior to diagnosis and 21\% (43 out of 202) were not satisfied about their GP's symptom recognition, believing this had led to a delay in diagnosis. Women also felt there was a lack of awareness generally in the public domain about ovarian cancer and its symptoms. Quotes illustrating these two themes are shown in Appendix A.

Routine care and treatments. Oncologists indicated that the most frequently used first-line treatment was carboplatin and paclitaxel (86\%; 56 out of 65$)$, and fatigue was its commonest side effect (55\%; 36 out of 65$)$. This was echoed in the patient survey where $70 \%$ (142 out of 202) of women receiving those drugs, cited both
Table 1a. Clinicians' characteristics $(n=66)$

\section{Country}

England

Northern Ireland

Scotland

Wales

$1(1 \%)$

$8(12 \%)$

$5(8 \%)$

Sex

Male

Female

$33(50 \%)$

$33(50 \%)$

Specialty

Medical oncologist

$44(67 \%)$

$22(33 \%)$

Main place of work

Designated gynaecology cancer centre

Cancer unit

Other NHS hospital

$51(77 \%)$

$12(18 \%)$

$3(5 \%)$

Main contract position

NHS Trust clinician

University clinical academic

Other

$54(82 \%)$

$11(17 \%)$

$1(1 \%)$

\section{Practice type}

\begin{tabular}{|l|l|}
\hline NHS only & $36(55 \%)$ \\
NHS and private & $30(45 \%)$
\end{tabular}

Number of patients treated annually with advanced OC (stages II-IV)

\begin{tabular}{|l|l|}
\hline$<30$ & $14(21 \%)$ \\
$31-60$ & $27(41 \%)$ \\
$>60$ & $25(38 \%)$
\end{tabular}

\section{Clinical trials activity}

Actively involved in clinical trials

Conducts early phase trials

Refers between 1-4 patients annually for early-phase trials

$59(98 \%)$

$21(35 \%)$

$29(73 \%)$

fatigue $(63 \% ; 127$ out of 202$)$ and hair loss $(63 \% ; 127$ out of 202$)$ as the most 'bothersome' side effects, followed by constipation (48\%; 97 out of 202) (Figure 2).

The first-ranked trigger that influenced oncologists' decisions to initiate a second course of treatment was symptomatic disease progression $(75 \% ; 49$ out of 65$)$. Second line and subsequent treatments for platinum-sensitive patients was usually carboplatin and paclitaxel $(63 \%$; 39 out of 62$)$; for partially platinum-sensitive patients, it was most often carboplatin with paclitaxel (3-weekly) (40\%; 25 out of 62$)$; or carboplatin with PLDH (24\%; 15 out of 62$)$; and PLDH was the treatment of choice for platinum-resistant patients $(68 \% ; 42$ out of 62$)$. The majority of women interviewed had received first- and second-line therapy ( $68 \% ; 138$ out of 202), but $15 \%$ (31 out of 202) had received four or more courses of chemotherapy (breakdown of chemotherapy regimens available Supplementary Table A).

Clinicians reported that fatigue was the most complained about and hardest to ameliorate side effect (50\%; 31 out of 62$)$; a finding also reflected in the patient interviews. Although many women were troubled by fatigue (63\%; 127 out of 202), only $32 \%$ ( 40 out of 127) received any support or advice for this symptom. In contrast, the majority of women (88\%; 71 out of 81$)$ concerned about their symptoms of nausea received practical assistance, usually in the form of anti-emetics. Helpful interventions were not so 


\begin{tabular}{|c|c|}
\hline \multicolumn{2}{|l|}{ Age } \\
\hline $\begin{array}{l}\text { Mean (s.d.) } \\
\text { Min-Max }\end{array}$ & $\begin{array}{c}63.5 \text { years }(9.6) \\
31-83 \text { years }\end{array}$ \\
\hline \multicolumn{2}{|l|}{ Education } \\
\hline $\begin{array}{l}\text { Secondary (up to age } 14-16 \text { years) } \\
\text { Further/higher }\end{array}$ & $\begin{array}{r}107(53 \%) \\
95(47 \%)\end{array}$ \\
\hline \multicolumn{2}{|l|}{ Marital status } \\
\hline $\begin{array}{l}\text { Married/civil partnership } \\
\text { Single/divorced/separated/widowed }\end{array}$ & $\begin{array}{r}132(65 \%) \\
70(35 \%)\end{array}$ \\
\hline \multicolumn{2}{|l|}{ Tumour stage } \\
\hline $\begin{array}{l}\text { I (with progression) } \\
\text { II } \\
\text { III } \\
\text { IV } \\
\text { Unknown }\end{array}$ & $\begin{array}{c}5(3 \%) \\
10(5 \%) \\
121(60 \%) \\
64(31 \%) \\
2(1 \%)\end{array}$ \\
\hline \multicolumn{2}{|l|}{ Time since diagnosis } \\
\hline $\begin{array}{l}\text { Mean (s.d.) months } \\
\text { Min-Max months }\end{array}$ & $\begin{array}{l}31.5(37.0) \\
1-233\end{array}$ \\
\hline \multicolumn{2}{|l|}{ Treatment } \\
\hline $\begin{array}{l}\text { Surgery } \\
\text { Radiotherapy } \\
\text { Hormone therapy }\end{array}$ & $\begin{array}{c}175(87 \%) \\
13 \text { (6\%) } \\
23(11 \%)\end{array}$ \\
\hline \multicolumn{2}{|l|}{ Total number of chemotherapy courses received } \\
\hline $\begin{array}{l}1 \\
2 \\
3 \\
4 \\
\geqslant 5\end{array}$ & $\begin{array}{l}82(41 \%) \\
56(28 \%) \\
33(16 \%) \\
17(8 \%) \\
14(7 \%)\end{array}$ \\
\hline Ever received $\mathrm{OC}$ treatment within a trial & $52(26 \%)$ \\
\hline Trials entered - mode (min-max) & $1(1-3)$ \\
\hline Receiving chemotherapy at time of assessment & $117(58 \%)$ \\
\hline Have comorbidity & $141(70 \%)$ \\
\hline \multicolumn{2}{|l|}{ Surgery } \\
\hline $\begin{array}{l}\text { No surgery attempted } \\
\text { Biopsy only/exploratory laparotomy } \\
\text { Awaiting surgery (after neo-adjuvant chemo) } \\
\text { Primary debulking surgery } \\
\text { Delayed primary debulking surgery (after neo-adjuvant } \\
\text { chemo) } \\
\text { Surgery at relapse } \\
\text { Hysterectomy prior to ovarian cancer }\end{array}$ & $\begin{array}{c}15(7 \%) \\
2(1 \%) \\
10(5 \%) \\
92(46 \%) \\
83(41 \%) \\
16(8 \%) \\
23(11 \%)\end{array}$ \\
\hline
\end{tabular}

forthcoming for those 'bothered' by constipation 51\% (49 out of 97). Worryingly, only $54 \%$ (68 out of 127) of women distressed by hair loss said they received sufficient information as to when and how their hair would fall out, and/or how to obtain an NHS wig. When participants were grouped into (1) those with experience of first-line therapy only $(n=61)$ and (2) those with experience of second and subsequent chemotherapies $(n=141)$, the proportions who reported troublesome side effects changed. Compared with Group 2, women in Group 1 experienced more fatigue (72\% vs $52 \%$ ); constipation (69\% vs 22\%); and hair loss (66\% vs 39\%).

Clinical trial participation. Most clinicians were engaged in clinical trials $(98 \%$; 59 out of 60 ), primarily ones in the NCRN

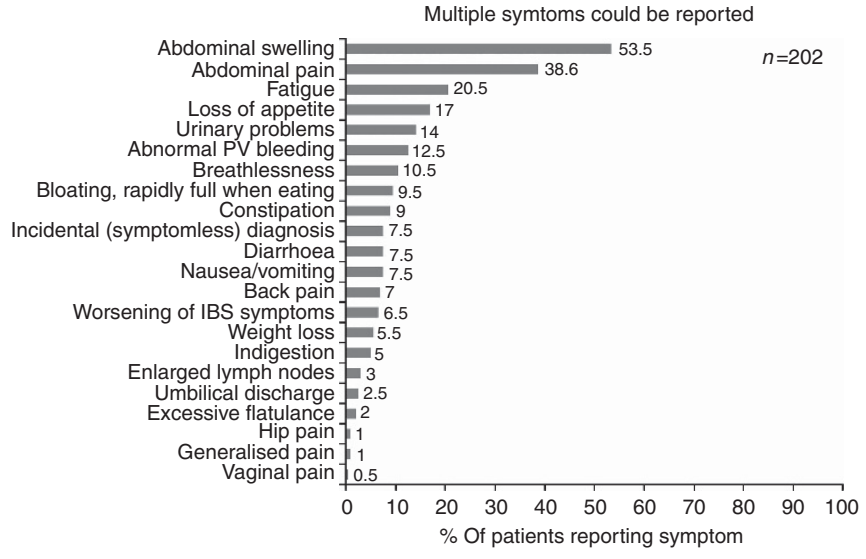

Figure 1. Distribution of symptoms prompting women to present to GPs.

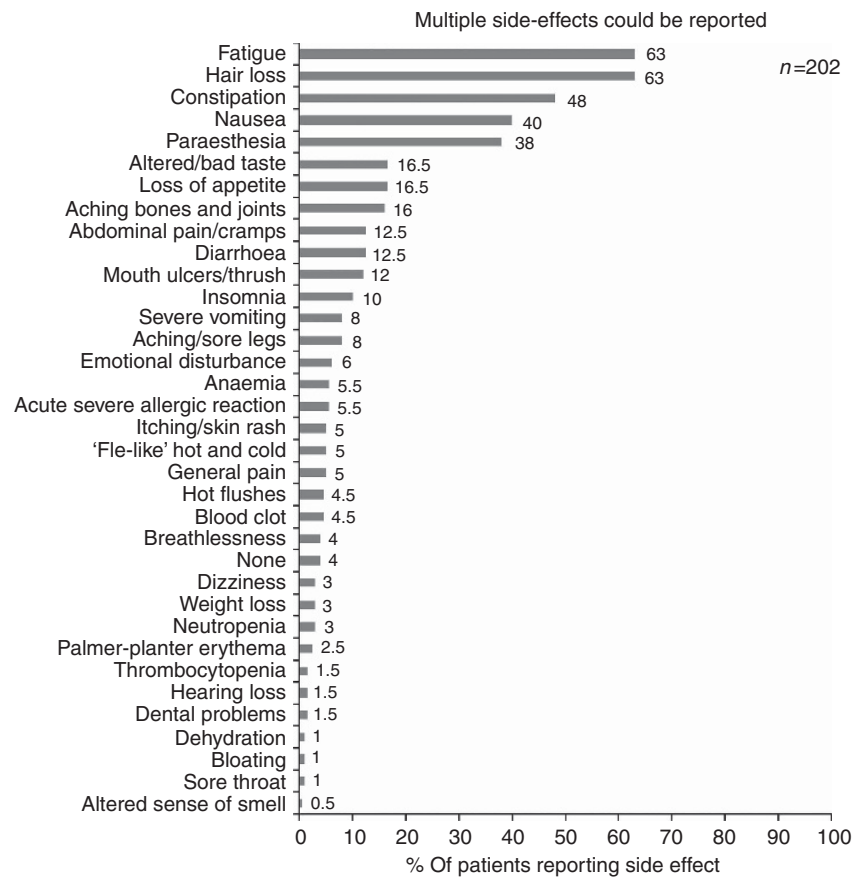

Figure 2. Distribution of the most bothersome side effects of first-line chemotherapy

portfolio (97\%; 57 out of 59), and some industry sponsored $(39 \% ; 23$ out of 59$)$. Only 35\% (21 out of 60 ) participated in Phase 1 studies, the majority of whom (57\%; 12 out of 21$)$ enrolled $>10$ patients a year. Others (73\%; 29 out of 40) referred between 1-4 patients to specialist centres for possible entry into early-phase trials. Treatment forms from the centres indicated that overall 25\% (50 out of 202) of women in the patient survey had received OC treatment within a clinical trial; $11 \%$ (23 out of 202) for first-line therapy and $22 \%$ (28 out of 125 ) for second-line.

Follow-up. Regular clinical follow-up after a course of chemotherapy was reported by the majority of oncologists, (97\%; 63 out of 65 ), and $66 \%$ (43 out of 65 ) measured CA125 levels routinely in clinic. Of those patients interviewed who were in follow-up $42 \%$ (85 out of 202), most reported attending clinics every 2 or 3 months (65\%; 55 out of 85); CA125 blood level tests (69\%; 59 out of 85$)$ were conducted more often than CT scans $(20 \% ; 17$ out of $85)$. Satisfaction with follow-up care (scale: $0=$ not at all satisfied$10=$ extremely satisfied) ranged between 2 to 10 with a mean of 
8.64 (s.d. 1.9). Two centres did not offer follow-up and relied on women to contact them if they had unmanageable symptoms.

Support. Oncologists rated the amount of support available in their hospitals for patients in terms of personnel and information services as high; with access to clinical nurse specialists (98\%; 59 out of 60 ), information centres (93\%; 56 out of 60$)$, dieticians $(87 \%$; 52 out of 60$)$ and psychologist/psychiatrists (80\%; 48 out of 60$)$.

Patients' views on information resources and receipt of support differed and depended on whether they were on or off active treatment. For example, 14\% (12 out of 85) of those off treatment compared with $3 \%$ (3 out of 117 ) on treatment did not have any contact with a specialist nurse. Also, 22\% (19 out of 85) off treatment had a telephone number for a nurse but never used it, compared with $9 \%$ (11 out of 117) of women on treatment. Patients' most usual forms of support were family and friends $(69 \% ; 139$ out of 202$)$ and GPs $(58 \% ; 117$ out of 202$)$, with only $32 \%$ (65 out of 202) relying on the hospital specialist nurse (Figure 3).

There was close agreement that in-house material about chemotherapy treatments was given to patients (oncologists $77 \%$; 46 out of 60 ) (patients $78 \%$; 158 out of 202 ). However, only $73 \%$ (148 out of 202) of patients said that they had received Macmillan booklets compared with clinicians (100\%; 60 out of 60 ) who reported that all patients are given them. The Macmillan Cancer Support website was recommended by $92 \%$ (55 out of 60 ) of oncologists and 49\% (99 out of 202) of women said that they had searched for information on OC independently, with 39\% (79 out of 202) using the internet; 14 out of $79(18 \%)$ had viewed the Macmillan site. Surprisingly few patients were aware of or had received information from any of the ovarian cancer charities $(6 \%$; 12 out of 202).

Maintenance therapy. At the time of the clinician survey, only three oncologists offered bevacizumab as maintenance therapy and this was reflected in the patient treatment forms, where a minority of patients (19\%; 38 out of 202) had ever received maintenance therapy and for 12 out of 38 patients (32\%), this was within a clinical trial. Thirteen oncologists also used endocrine therapies (tamoxifen, letrozole and anastrozole) in ER-positive patients. Twenty-three out of 202 (11\%) women had received endocrine treatment at some point, although not necessarily as maintenance therapy.

A majority 50 out of 60 (83\%) oncologists viewed maintenance therapy positively albeit based on data regarding PFS benefits shown in trials. There were interesting differences between the minimum gains in PFS based on what the clinicians thought worthwhile, compared with the gains they believed that their patients would consider (see Table 2). All clinicians said that they would feel more encouraged about offering maintenance therapy if improvements in OS were shown.

At the interview, participants were presented with a hypothetical scenario, asking: 'If you were offered a drug that could prolong your life, but it gave you side effects such as fatigue, feeling sick,

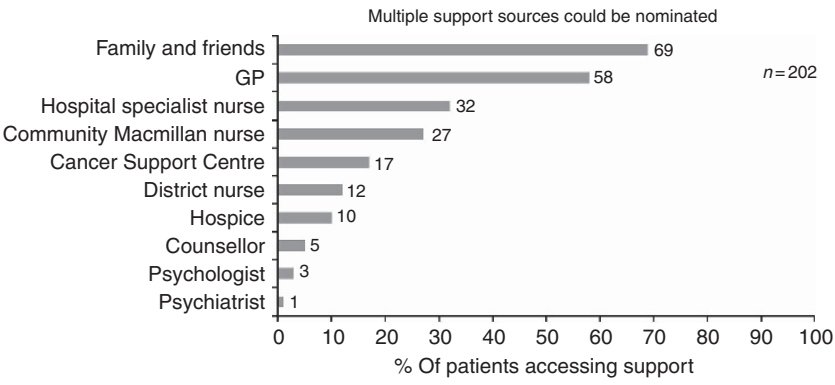

Figure 3. Distribution of support sources women relied upon. numbness or tingling in fingers and toes, how many extra months of life would you want to make having the treatment worthwhile?'

Almost a quarter (21\%; 42 out of 202) were unable/did not want to give an answer to the question, a third (52 out of 160) said 1-2 months, 6\% (10 out of 160) 3-4 months, 31\% (49/160) 5-6 months, and $31 \%(49 / 160) \geqslant 7$ months (Table 3$)$. However, when asked: 'If you were offered a drug that could improve your quality of life but might not prolong it, would you be prepared to try it?', $86 \%$ (173 out of 202 ) of women said they would be willing to try a drug that improved their QoL even if it would not prolong their life.

When asked what was the most important aim of treatment to them, 33\% (67 out of 201) said QoL, 9\% (19 out of 201) length of life and $57 \%$ (115 out of 201) said both were equally important.

QoL Questionnaire data. The mean global score on the EORTC QLQC30 was 62.7 (s.d. 20.3); results for the subscales within this measure are shown in Supplementary Table 4 together with scores for the OV28 symptom scales alongside comparison scores of a reference group from the EORTC manual. These scores show that the sample were representative of women with advanced OC disease. The QLC30 global score was lower (poorer QoL) in women without a partner $(\beta=-5.9, P$-value $=0.04)$, and those on treatment $(\beta=-10.9, P$-value $<0.001)$. Neither age group (under and over 60 years) or education (secondary/higher) influenced the global score.

\begin{tabular}{|c|c|c|c|c|}
\hline & \multicolumn{4}{|c|}{ Months } \\
\hline Question & $\begin{array}{l}1-2 \\
(\%)\end{array}$ & $\begin{array}{l}3-4 \\
(\%)\end{array}$ & $\begin{array}{l}5-6 \\
(\%)\end{array}$ & $\begin{array}{l}7+ \\
(\%)\end{array}$ \\
\hline $\begin{array}{l}\text { What minimum gain in PFS would } \\
\text { make you feel it worthwhile to offer } \\
\text { maintenance therapy? }(n=50)\end{array}$ & 0 & $19(38)$ & $24(48)$ & 7 (14) \\
\hline $\begin{array}{l}\text { What do you think your patient } \\
\text { would consider worthwhile? }(n=50)\end{array}$ & $12(24)$ & $26(52)$ & $9(18)$ & $3(6)$ \\
\hline $\begin{array}{l}\text { What minimum gain in OS would } \\
\text { make you feel it worthwhile to offer } \\
\text { maintenance therapy? }(n=60)\end{array}$ & $2(3)$ & $36(60)$ & $15(25)$ & $7(12)$ \\
\hline $\begin{array}{l}\text { What do you think your patient } \\
\text { would consider worthwhile? }(n=60)\end{array}$ & $25(42)$ & $23(38)$ & $5(8)$ & $7(12)$ \\
\hline
\end{tabular}

Table 3. Patients views on maintenance therapy

\begin{tabular}{|c|c|c|c|c|}
\hline $\begin{array}{l}\mathbf{N}=160(42 ; 21 \%) \\
\text { unable to answer } \\
\text { question }\end{array}$ & $1-2$ & $3-4$ & $5-6$ & $7+$ \\
\hline $\begin{array}{l}\text { How many extra months life } \\
\text { would you want to make } \\
\text { having maintenance } \\
\text { treatment worthwhile? }\end{array}$ & 52 (33\%) & $10(6 \%)$ & 49 (31\%) & 49 (31\%) \\
\hline $\mathbf{N}=\mathbf{2 0 2}$ & \multicolumn{2}{|c|}{ Yes } & \multicolumn{2}{|c|}{ No } \\
\hline \multirow{2}{*}{$\begin{array}{l}\text { Would you try a drug that } \\
\text { could improve the quality } \\
\text { of your life but might not } \\
\text { prolong it? }\end{array}$} & \multicolumn{2}{|c|}{$173(86 \%)$} & \multicolumn{2}{|c|}{$19(9 \%)$} \\
\hline & \multicolumn{2}{|c|}{ Quality of life } & $\begin{array}{l}\text { Length } \\
\text { of life }\end{array}$ & Both \\
\hline $\begin{array}{l}\text { What is most important to } \\
\text { you? ( } 1 \text { missing) }\end{array}$ & \multicolumn{2}{|c|}{67 (33\%) } & $19(9 \%)$ & 115 (57\%) \\
\hline
\end{tabular}


A plot of the proportion of patients indicating that they received

'quite a bit/very much' information on the topics listed in the EORTC INFO25

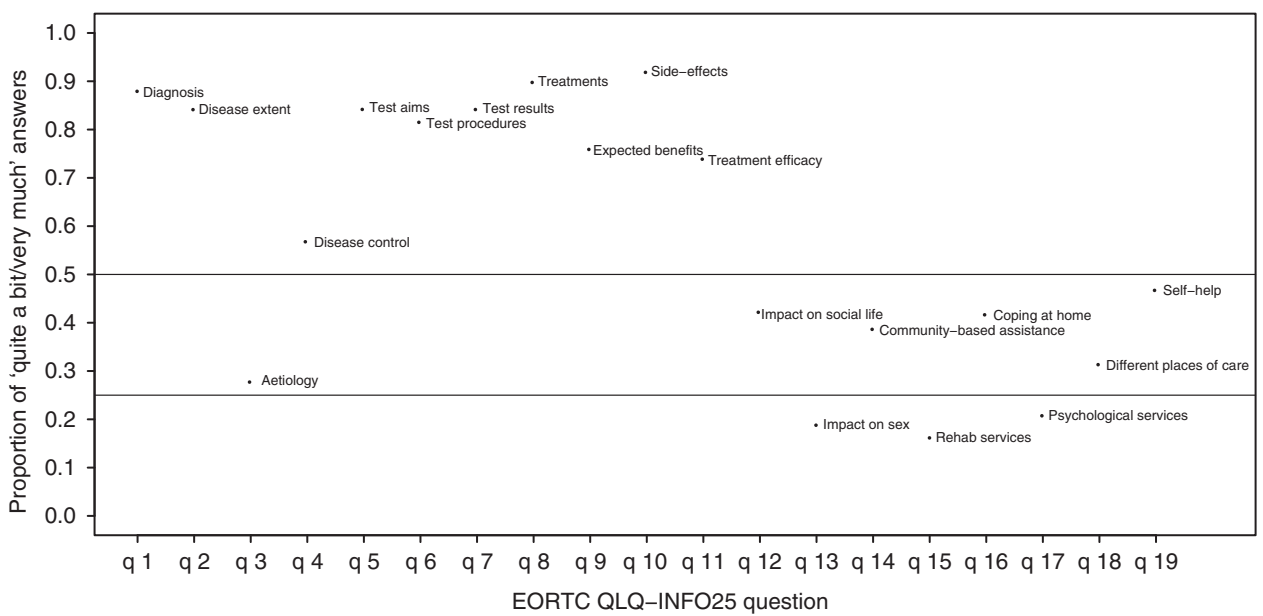

Figure 4. EORTC INFO needs.

The summary score from the OV28 symptom scales for the hormonal items was influenced by age, with older women less likely to report hot flushes $(\mathrm{OR}=0.25, P$-value $<0.001)$. Disease was a burden to over $43 \%$ of patients, disease and treatment burden were reported more often in those with higher education $(\mathrm{OR}=1.77, \quad P$-value $<0.049 ; \quad \mathrm{OR}=2.7, \quad P$-value $<0.001$ respectively).

Figure 4 shows the proportion of patients who responded 'quite a bit/very much' to having received sufficient information about the topics listed on the EORTC INFO25 questionnaire. Noticeably $\geqslant 80 \%$ indicated that they had received adequate information on diagnosis, disease extent, tests, treatments and side effects of treatments. However, fewer women reported receiving sufficient information about disease control (58\%), how to cope at home $(40 \%)$, what help was available outside the hospital $(40 \%)$ and how to access psychological services (20\%). The responses to the information questionnaire were not influenced by age group, on/off treatment, partner/no partner, or education.

Participants with a high global score on INFO25, those over 60 years and those with higher education levels were more likely to cite $\mathrm{QoL}$ as more important $(\mathrm{OR}=1.03, P=0.02 ;(\mathrm{OR}=2.44$, $P=0.02$ and $(\mathrm{OR}=2.43, P=0.011$, respectively). When asked "How many extra months of life would you want to make having maintenance treatment worthwhile?', only global QoL score influenced choice. Those with a lower (poorer) global EORTC QLQ30 score (first quartile $=50$ ) were more likely to want a treatment to offer more time for it to be worthwhile $(\mathrm{OR}=1.61$, $P$-value $=0.025)$ compared with those with a higher QoL score (third quartile $=50$ ).

\section{DISCUSSION}

These surveys provide a summary of oncologists' treatment practices across the UK and a comparison of their patients' experiences. Many patients presented with late-stage disease with abdominal pain and swelling. Almost a quarter were not satisfied with the way their GP dealt with their concerns, often diagnosing irritable bowel syndrome or constipation. These findings accord with the Cancer Patient Experiences Survey 2011/12 (DoH 2012); $37 \%$ of ovarian cancer patients saw their GP more than twice about their symptoms before being referred for diagnostic tests, compared with just $8 \%$ of breast cancer patients. Our current interviews also revealed patients felt strongly that there was a lack of publicity about the signs and symptoms of ovarian compared with breast and more recently lung cancer. One participant made a salient point that some advertisers promote bloating or urinary incontinence as quite normal for women over 50 years, and that drinking/wearing certain products can help. Women often blamed themselves for ignoring such symptoms, and consequently presenting late at diagnosis when disease had spread.

Treatments offered across the UK were fairly similar. A large proportion of oncologists were engaged in clinical trials and $26 \%$ (52 out of 202) of patients interviewed had received OC treatment within a trial; 12 out of $52(23 \%)$ involved trials of maintenance therapy. Fatigue was the most troublesome side effect for patients, and clinicians acknowledged that it is difficult to treat. Patients were aware of this and appreciated healthcare professionals' (HCP) advice and/or regular enquiry as to how they were coping.

It was noticeable that women who had received only one course of chemotherapy reported side effects as being more troublesome than did those who had experience of more than two further lines of treatment. Intuitively this makes sense, as women might be more prepared the second time and devised ways to cope with the unwanted side effects. Although some centres offered an excellent supportive service to women, with induction visits to the chemotherapy suite, and discussing in detail the treatments and side effects, others were lacking.

One surprising finding was that hair loss was not uniformly well dealt with in terms of advice and wig-fitting. A significant proportion of the women greatly disturbed by hair loss were unprepared as to how and when their hair would fall out and/or how and where to obtain a wig in the NHS. Providing a leaflet or cursory mention that hair loss is an inevitable consequence of treatment was not helpful for patients.

Patients' views about information resources and receipt of support differed from that reported by oncologists in the online survey as available at their hospital/centre. Few women made use of the specialist nurse during the period following the end of a course of chemotherapy or at their follow-up appointment. Several patients, no longer having active treatment expressed a feeling of abandonment and felt a need for regular contact in the form of a supportive telephone call. This was more noticeable in women without a partner, who overall reported a poorer QoL. The majority of women relied on family and friends for support. The Cancer Patient Experiences Survey 2011/12 reported that although $91 \%$ of ovarian cancer patients were given the name of 
the specialist nurse in charge of their care, only $68 \%$ said that she was easy to contact. The survey also revealed that $40 \%$ of women with ovarian cancer were not given written information about their cancer (DoH 2012).

The information needs of the women we interviewed was met for most of the tangible, practical aspects of treatment and care, such as diagnosis, tests and treatments, but much less so for the psychosocial aspects, such as whether the disease was under control and how to cope at home. This is an area that needs greater attention in view of the fact that maintaining quality of life, together with symptom control is the main goal for these patients.

The majority of oncologists were positive about maintenance therapy based on PFS benefits, but availability was a barrier to its prescription. The clinician survey was conducted before the decision to accept bevacizumab for advanced OC onto the priority list of the Cancer Drugs Fund (CDF) in England, and few patients interviewed had received the drug outside of a cilinical trial setting. Patients' views were similar to clinicians regarding OS, with $62 \%$ requiring a gain of $\geqslant 5$ months of life to make the treatment worthwhile. It should be noted that PFS gains were not explored in the patient interview as PFS is not a familiar term and rarely used by clinicians when discussing treatments with patients (Fallowfield and Fleissig, 2012).

Two previous studies have attempted to explore ovarian cancer patients' preferences for care, one focussed exclusively on patients' choice regarding different first-line therapies (Elit et al, 1996), the other examined treatment preferences in recurrent ovarian cancer, tackling issues of quality and quantity of life (Donovan et al, 2002). The latter found that on average patients would switch from 'salvage therapy' to palliative care when the median survival associated with therapy was reduced to 5 months. There was no association between any dimensions of QoL and the time point at which patients would switch to palliative care. However, a regression analysis showed that as family and friends' involvement increased, the period of survival associated with salvage therapy women still found acceptable decreased. In the current study, single women with poorer global QoL scores were more likely to want a treatment to offer more time for it to be worthwhile than those with higher QoL scores.

In our interviews, patients assumed maintenance therapy would have similar toxicity to chemotherapy and it is possible that newer biological agents with different side effects may change patients' perceptions. Shorter timespan gains could be perceived as worthwhile for therapies with less burdensome side effect profiles. In the recent analysis of the ICON7 trial, QoL was measured using the EORTC QLQ C30 and OV28. Results showed that bevacizumab continuation treatment was associated with a small but clinically significant decrement in Global QoL compared with standard treatment (Stark et al, 2013). However, the authors note that the Gynaecological Oncology Group (GOG 218) double-blind, placebo control study used a different instrument for measuring QoL (FACT O) and did not report a clinically important difference between standard chemotherapy + bevacizumab vs standard chemotherapy + placebo. They suggest that the difference between the study results is because of disruption to women's lives from delivery of continuation therapy that was reflected in poorer role functioning, financial worries, attitudes to disease to treatment, hormonal symptoms and rash. A recent commentary on the ICON7 trial advocates that women with ovarian cancer should be asked to assess the inherent trade-offs implicated in new treatments (Havrilesky and Abernethy, 2013).

Balancing QoL with the length of it was most important to $57 \%$ (115 out of 201 ) of patients, another third (33\%; 67 out of 201) indicated that QoL was the priority, and for just 9\% (19 out of 201) length of life was paramount. This distribution is similar to a previous report of preferences among patients with advanced cancer where 55\% (252 out of 459) equally valued QoL and length,
27\% (123 out of 459) most valued QoL and 18\% (84 out of 459) length of life (Merepol et al. 2008).

Limitations of the study. Single time-point survey data are sensitive to policy changes in relation to clinical practices and we acknowledge this in relation to the use of bevacizumab. Another limitation is that we are not directly matching the views and practices of each oncologist that completed the clinician survey with the views captured from patients they have necessarily treated. However, by sampling from 16 hospitals in England, Scotland and Wales, both large specialist cancer centres and small district general hospitals, we hope to have gathered a good range of patient experiences. We recognise that assuming maintenance therapy to have toxicity equivalent to chemotherapy influences the extrapolation of the patient preferences observed and further work is needed to explore reactions to markedly different side effect profiles.

\section{CONCLUSIONS}

These UK surveys give a view of the treatments and care offered by oncologists and received by women with advanced ovarian cancer. Although the majority of women, once a diagnosis had been established were happy with their care and treatment, a fair proportion gave worrying reports of a lack of information and support. These findings concur with much of the recent ovarian cancer quality profile summaries produced from the National Cancer Patient Experience Survey (CPES) for 2011/12. Increasing women's awareness of OC symptoms, together with earlier diagnosis may help make this disease more treatable.

\section{ACKNOWLEDGEMENTS}

We thank the clinicians and patients who gave their time to participate in the surveys. Professors Gore and Ledermann for help with establishing the content of the clinician questionnaire, together with the clinicians and research nurses at the $16 \mathrm{UK}$ centres, and Carolyn Langridge, data manager for the project. $S$ Banerjee acknowledges support from the National Institute of Health Research (NIHR) Biomedical Research Centre. C Gourley acknowledges support for the Edinburgh Cancer Centre from Cancer Research UK and personal fellowship support from the Scottish Funding Council and the Scottish Chief Scientist's Office. We thank Roche Products Ltd for providing an unrestricted educational grant to enable us to conduct the work.

\section{DISCLAIMER}

Neither the funding body nor the sponsor had any role in study design; in the collection, analysis and interpretation of data; in the writing of the report; and in the decision to submit the article for publication.

\section{REFERENCES}

Aaronson NK, Ahmedzai S, Bergman B, Bullinger M, Cull A, Duez NJ, Filiberti A, Takeda F (1993) The European Organization for Research and Treatment of Cancer QLQ-C30: a quality-of-life instrument for use in international clinical trials in oncology. J Natl Cancer Inst 85(5): 365-376.

Arraras JI, Greimel E, Sezer O, Chie W-C, Bergenmar M, Costantini A, Young T, Velikova G (2010) An international validation study of the EORTC QLQ-INFO25 questionnaires: an instrument to assess the information given to cancer patients. Eur J Cancer 46: 2726-2738.

Basch E, Abernethy AP (2011) Supporting clinical practice decisions with real-time patient-reported outcomes. J Clin Oncol 29: 954-956. 
Burger RA, Brady MF, Bookman MA, Fleming GF, Monk BJ, Huang H, Mannel RS, Liang SX (2011) Incorporation of bevacizumab in the primary treatment of ovarian cancer (GOG-0218 study. N Engl J Med 365: 2473-2483.

Cancer Research UK (2012) Ovarian cancer statistics www.cancerresearchuk. org/cancer-info/cancerstats/types/ovary/(accessed 2 Nov 2012).

Coleman MP, Forman D, Bryant H, Butler J, Rachet B, Maringe C, Nur U, Tracey E, Coory M, Hatcher J, McGahan CE, Turner D, Marrett L, Gjerstoff ML, Johannesen TB, Adolfsson J, Lambe M, Lawrence G, Meechan D, Morris EJ, Middleton R, Steward J, Richards MA. the ICBP Module 1 Working Group (2011) Cancer survival in Australia, Canada, Denmark, Norway, Sweden, and the UK, 1995-2007 (the International Cancer Benchmarking Partnership): an analysis of population-based cancer registry data. Lancet 377: 127-138.

Cox A, Bull E, Cockle-Hearne J, Knibb W, Potter C, Faithfull S (2008) Nurse led telephone follow up in ovarian cancer: a psychosocial perspective. Eur J Oncol Nurs 12: 412-417.

Cox K, Wilson E, Health L, Collier J, Jones L, Johnston I (2006) Preferences for follow-up after treatment for lung cancer. Cancer Nurs 29: 176-187.

Department of Health National Cancer Patient Experience Survey 2011/12 - National Report 17 August 2012 www.dh.gov.uk/publications.

Donovan KA, Greene PG, Shuster Jr. JL, Partridge EE, Tucker DC (2002) Treatment preferences in recurrent ovarian cancer. Gynecolog Oncol 86: 200-211.

du Bois A, Rochon J, Pfisterer J, Hoskins WJ (2009) Variations in institutional infrastructure, physician specialization and experience, and outcome in ovarian cancer: a systematic review. Gynecol Oncol 112(2): 422-436.

Elit L, Levine M, Gafni A, Whelan T, Doig G, Streiner D, Rosen B (1996) Patients' preferences for therapy in advanced epithelial ovarian cancer: development, testing, and application of a bedside decision instrument. Gynecol Oncol 62: 329-335.

Fallowfield LJ, Fleissig A (2012) The value of progression-free survival to patients with advanced-stage cancer. Nat Rev Clin Oncol 9: 41-47.

Fayers PM, Aaronson NK, Bjordal K, Groenvold M, Curran D, Bottomley A. The EORTC Quality of Life Group (2001) The EORTC QLQC30 Scoring Manual, 3rd Edn. European Organisation for Research and Treatment of Cancer: Brussels.

Kristensen G, Perren T, Qian W, Pfisterer J, Ledermann JA, Joly F, Carey MS, Beale PJ, Cervantes A, Oza AM. and GCIG (2011) Results of interim

\section{APPENDIX A}

\section{Theme 1: delay in GP recognition of OC symptoms}

'The GP was hopeless, kept telling me I had constipation, I went back many times and I knew I had something seriously wrong. In the end I went to a private gynaecologist who did investigations and scans that found the cancer' ID70, 74 years

'I went to the GP repeatedly with lower tummy pains before it then started to swell, once that got bad the GP referred me for investigations' ID98, 61 years

'GP took a long time to recognise that my symptoms were something more serious than a urinary tract infection' ID153, 83 years

'I was going to the GP for more than a year reporting pain, diarrhoea, weight loss, feeling full quickly when eating, it was treated as irritable bowel syndrome' ID163, 64 years

'Very disappointed with the GP and the way my symptoms were ignored and not investigated until it was all too late' ID 184, 58 years

'What made me mad was the GP, he didn't listen to me when I went to him, he just kept saying I had constipation, I knew I didn't, I now have a different GP' ID 191, 46 years

Theme 2: general lack of awareness and good publicity about symptoms of OC. 'I feel I was never aware of ovarian cancer, I had no idea about the signs and symptoms, it really, really needs to be publicised, you hear lots about breast cancer' ID05, 73 years analysis of overall survival in the GCIG ICON7 phase III randomised trial of bevacizumab in women with newly diagnosed ovarian cancer. (Abstract). In: Proceedings of the Annual Meeting of the American Society of Clinical Oncology (ASCO); June 3-7 Chicago, IL, USA.

Greimel E, Bottomley A, Cull A, Waldenstrom A-C, Arraras J, Chauvenet L, Holzner B, D'haese S (2003) An international field study of the reliability and validity of a disease-specific questionnaire module (the QLQ-OV28) in assessing the quality of life of patients with ovarian cancer. EJC 39: 1402-1408.

Havrilesky LJ, Abernethy AP (2013) Quality of life in ICON7: need for patients' perspectives. Lancet Oncol (2013) 14(3): 183-185.

Lutgendorf SK, De Geest K, Bender D, Ahmed A, Goodheart MJ, Dahmoush L, Zimmerman MB, Sood AK (2012) Social influences on clinical outcomes of patients with ovarian cancer. J Clin Oncol 30(23): 2885-2890.

Meropol NJ, Egleston BL, Buzaglo JS, Benson III AB, Cegala DJ, Diefenbach MA, Fleisher L, Trinastic J (2008) Cancer patients' preferences for quality and length of life. Cancer 113: 3459-3466.

National Institute for Health and Clinical Excellence (2003) Guidance on the use of paclitaxel in the treatment of ovarian cancer. NICE technology appraisal guidance 55. National Institute for Health and Clinical Excellence: London, UK.

Perren TJ, Swart AM, Pfisterer J, Ledermann JA, Pujade-Lauraine E, Kristensen G, Carey MS, Oza AM (2011) A phase 3 trial of bevacizumab in ovarian cancer (ICON7 study). N Engl J Med 365: 2484-2496.

Stark D, Nankivell M, Pujade-Lauraine E, Kristensen G, Elit L, Stockler M, Hilpert F, Cervantes A, Brown J, Lanceley A, Velikova G, Sabate E, Pfisterer J, Carey MS, Beale P, Qian W, Swart AM, Oza A, Perren T (2013) Standard chemotherapy with or without bevacizumab in advanced ovarian cancer: quality-of-life outcomes from the International Collaboration on Ovarian Neoplasms (ICON7) phase 3 randomised trial. Lancet Oncol 14(3): 236-243.

This work is published under the standard license to publish agreement. After 12 months the work will become freely available and the license terms will switch to a Creative Commons AttributionNonCommercial-Share Alike 3.0 Unported License.

'seeing adverts on TV and in magazines that tell women to eat yoghurt for bloating makes me very angry and also the adverts that say women commonly have urinary problems and should just buy panty pads annoys me too' ID30, 58 years

'there needs to be much greater general awareness about ovarian cancer in GPs' surgeries, but also elsewhere for the public, like they have for breast cancer or now they are making us more aware of the lung cancer symptoms' ID41, 70 years

'Not enough general information at the GP surgery about ovarian cancer, not enough awareness in general' ID66, 66 years

'I don't think there is enough awareness about the illness amongst women in general. There needs to be more information and education, me and my friends had no idea about it, that I had symptoms of it for probably a long time. There is a lot of ignorance in women about the symptoms' ID82, 72 years

'My diagnosis came as a complete shock, not aware of ovarian cancer, breast cancer is in the newspapers more' ID141, 67 years

'Ovarian cancer is not something that I know much about, don't know the symptoms, not publicised much, people don't talk about it' ID148, 81 years

'Breast cancer dominates in the news, lots of support and funds raised. Ovarian cancer doesn't seem to have the same sort of impact. OC seems to be kept low key. Never much in the press. Need to publicise it more' ID178, 50 years 